\title{
IV. An analysis of the waters of two mineral Springs at Lemington Priors, near Warwick; including experiments tending to elucidate the origin of the muriatic acid
}

\section{William Lambe M.A.}

To cite this article: William Lambe M.A. (1798) IV. An analysis of the waters of two mineral Springs at Lemington Priors, near Warwick; including experiments tending to elucidate the origin of the muriatic acid , Philosophical Magazine Series 1, 1:4, 350-361, DOI: $10.1080 / 14786447808676851$

To link to this article: http://dx.doi.org/10.1080/14786447808676851

曲 Published online: 25 Jan 2010.

Submit your article to this journal $₫$

凹 Article views: 3

Q View related articles $\sqsubset$ 


\section{[ 350$]$}

IV. An Antlyis of the Waters of two Minorat Springs at Lemington Priors, near Wartuick ; including Experiments tending to elacidate tbe Origin of tbe Muriatio Acid. By Wilura M Lamee, M. A. late Fellowo of St. Jobri's ColLege, Cambridge. From tha Memoirs of the Literary and Philofophical Society of Manchefter, Vol. V. Part I.

[Concluded trom p. 269.]

XI. FUTTHER PROPERTIES OF THE OXYOENATED MURIAT OFIRON.

THE facts I have related are unqueltionable: it was in the latter end of 1795 that I firt made the obfervation on the effect of bepatifed water upon iron: fince then I have verified it repeatedly, and particularly in the month of December 1796 , with fome very purt iron, and in the prefence of two gentlemen, very competent judges, one of whom affifed at every part of the procefs. Still it has been alked, How is it poffible that this folution can contain muriatic acid, feeing that nitrat of filver, that moft deficate teft of this acid, is hardly affected by it? To this it might perhaps be a fufficient reply, that it is unreafonable to oppofe a mere analogy to the direct evidence of the renfes; particularly in a new cafe, where we have found fome of the analogies beft eftablifbed in chetniftry to fail. But let us recur once more to experiment.

I formed again fome oxygenated muriat of iron. I fuffered the acid to remain on the oxyde about 24 hours; then poured off the liquor, and evaporated the fait to drynefs to expel the fuperfluous acid : the falt, which deliquefces inftantly on cooling, was rediffolved in a little diftilled water. I. I tried the folution with the acetite of lead : not the fmalleft cloud was produced. 2. The folution was then tried with the nitrat of filver: a little white curdy matter was formed. 3. A tea-1poonful of the folution was diffufed through two or three ounces of diftilled water, and then tried with the nitrat of filver : a very flight cloud was formed, and a minute purple precipitate fell, but not till after fame hours. The appear- 
ance was not fo ftrong, nor the precipitate fo copious, as when nitrat of fluer is droppét into ordinary rain water. $\rightarrow$ Thefe experiments evince, that this falt either does not decompofe the falts of lead and filver, or that the new compounds are foluble in water. The firft is abfolutely conclufive: as to the fmall appearance of decompofition in Exp. 2 and 3 , be it confidered how difficult it is to prevent a minute quantity of common acid from pafing over in the diftillation of the oxygenated acid; and how readily this acid itfelf is decompofed : add to this the imperfect oxydation, perhaps, of the iron. If thefe circumftances are duly weigh = ed; it feems probable, that this falt, when quite pure, would nat at all fenfibly decompofe nitrat of filver. A flight impurity cannot be detected by acetite of lead, as a fmall quantity of muriat of lead is foluble in water.

\section{XI1. FURTHER CONSIDERATIONS ON THE HEPA-} TISED SOLUTIONS.

Befides the oxygenated falts, I think it probable, that thefe folutions retain fome fulphur; but under what form, or in what combination, it is not eafy to fay. The refiduum, after evaporation, has a peculiar fmell, whereas the pure falts are inodorous. The ftain left upon filver by the refiduum ought, perhaps, to be attributed to this caufe. Alfo, the white matter formed by the decompofition of oxygenated muiriat of mercury feems to be a combination of fulphur and mercury. In proof of this it may be remarked, that the precipitate of this falt difiolved in fimple hepatifed water is white. Further, it is doubtlefs true, that if hepatifed water have a fnall quantity of acid mixed with it, the folution of iron ftrikes a purple colour with galls. To point out the origin of this colour, mix iron flings and fulphur not wafhed, and form them into a pafte with a little water, ard let them remain together fo: fome hours: put the paite into water, and filtrate: this water now ftrikes a purple colour 
with galls. Now, common fulphur is always contaminated with a little fulphuric acid; and, as neither hepatic gas nor oxygenated falt is here concerned, the effect muit be attributed to the acid and the fulphur. If this water be evaporated, it leaves a matter which does no deliquefce; but which emits the fame fmell as the refiduum of the hepatifed folutions. To fhow that the acid is neceffary to the production of the purple colour, let the fulphur be well wafhed with diftilled water before it is mixed with the iron; and it will be found that no fuch colour can be now produced. The following fact feems to prove that fulphur may be retained in water, in the form neither of fulphur nor of hepatic gas : it is an additional proof how effentially the oxygenated differs from all the common falts of iron. I faturated a dilited folution of oxygenated muriat of iron, which fcarcely affected nitrat of filver, with hepatic gas. A white precipitate fell, but fo minute that it was impoffible to collect it, nor did it deftroy the tranfparency of the water: hence I think it probable that, if the falt were quite perfect, it would not be fenfibly affected by hepatic gas. I now boiled the liquor, to expel the gas, till it wholly loft its hepatic fmell. The liquor was again tried with nitrat of filver; and there was a copious depofition, but of a dark brownith colour. It feems certain, then, that fome fulphur is retained by the folution, which cannot be expelled by boiling.

XII. THE NEUTRAL SALTSOFTHE WATER: MURIAT OF MAGNESIA, MURIAT OF SODA, SULPHAT OF SODA.

A gallon of the water was evaporated to drynefs; the deliquefcent falts were feparated from the non-deliquefcent ; and each of the falts which were thus obtained was carefully examined. Thus, by proceffes which are fufficiently known, it was found that the gallon of water contains of miriat of magnefia 11.5 grains nearly; muriat of foda $43^{\circ}$ grains; fulphat of foda $55^{2}$ grains. 
The triple compound of which I have treated, is mixed with the deliquefcent falt of magnefia, but not wholly; for it may be difcovered with the non-deliquefcent falts, though thefe have been feparated carefully by fpirit of wine. The tartrite of pot-ah indicates it in both. Oxalic acid loes the fame thing, feparating a white powder with fome cryftalline grains which are the oxalat of manganefe. (See Bergman, Differt. viii. 24.)

\section{THE RESIDUUM OF DIFFICULT SOLUTION.}

After thefe falts had been feparated there remained a large refiduum, which was not foluble except in a great quantity of water. This has a cryftalline form like fulphat of lime; and of the ufual reagents thowed it, in fact, to contain both lime and fulphuric acid. But the weight of this refiduum, from a gallon of water, was no lefs than 1 I 2 grains : a larger quantity than could be diffolved in a gallon of water, if it were pure fulphat of lime. If it be confidered that the water requires fome evaporation before thefe cryftals begin to feparate, the proportion is fill more increafed. There muft be, therefore, fomething peculiar in the compofition of the falt, or in the foluble powers of the water. Other experiments fhow the fame thing. I. Sulphuric acid dropped into the water precipitates copiounly fulphat of lime. This cannot be effected by the decompofition of the muriat of lime: fince we have already feen that no fuch falt is to be found (xIII). Indeed it cannot exift in the fame folution with fulphat of foda, as thefe falts decompofe each other* 2. Sometimes a more unexpected appearance than this

* It is astonishing that this fact should have been neylected. and that in recent publications. Mr. Schmeisser, in his analysis of the waters of Kilburn Wells (Phil. Transac.), has joined together sulphat of soda, sulphat of magnesia, and muriat of lime, as being contained in these waters. Dr. Garnett has also put into the composition of the sulphur well at Harrowgate sulphat of magnesia and muriat of lime; an error the more unaccountahle, as Bergman has expressly remarked this decomposition in his Disertation on the Analysis of Waters. See Dissekt. ii. 7. M. 
takes place. It is, that precipitate, feemingly like the former, has been made by the addition of the muriatic acid : but by the addition of more acid the precipitate is rediffolved. Sometimes, indeed moft commonly, I have not been able to effect this appearance.

It was natural to expect the folution of any further inncommon obfervation in the fame matter that had already explained fo much. 3. I accordingly digefed fulphat of lime in the hepatifed folutions of iron and manganefe; and I found that the Jatter had a very ftrong folvent power. After the liquor had been filtered, fulphat of lime was plentifully precipitated by fulphuric acid. The folution of iron feems to have fomething of a fimilar property; but as it is very fmall, and as iron has almoft always a little manganere united with it, it is at leaft uncertain whether the whole effect ought not to be attributed to manganefe.

It remains to compare this remark with the effects of the artificial oxygenated falts; and thus to confrm, if confirmation were needed, the analogy which I have laboured to eftablifh. 4. Sulphat of lime was digefted with the oxygenated muriat of manganefe and diftilled water by a gentle heat : after $24^{\circ}$ hours the clear liquor was feparated: into this I dropped a little fulphuric acid; by degrees a large quantity of fulphat of lime was feparated. Muriatic acid was dropped into the fame liquor, but it did not feparate any thing. The oxygenated muriat of iron poffeffed the fame property, but in fo fmall a degree, that here again I am inclined to attribute this power to a little manganefe attached to the iron. It follows from thefe facts, that the large quantity of fulphat of lime is kept in folution by the falt of manganefe. And a further examination of the refiduum itfelf fhows that it contains the triple falt of manganefe and iron. 5. Some of the refiduum was perfectly edulcorated, and fulphuric acid was dropped upon it; the vapours of muriatic acid arofe, and were rendered evident by paper moiftened with ammoniac or with fimple water. To the fulphuric acid, 
acid, which was ufed in this experiment, was added fome diftilled water, and the liquor was filtrated: it was then Caturated with an alkali; a fmall precipitate fell, which was proved (by the ufual methods) to contain both manganefo and iron.

6. I bave noticed a variation (2.) in the effeet of muriatic acid when added to the water. I have obferved a fimilarvariety in the refiduum itfelf; which is, that fometimes it has been found foluble in the muriatic acid: when this happens, the addition of an alkali precipitates the refiduum in its original cryftalline form ; and this it does before the acid is faturated. But moft commonly the muriatic acid does not diffolve it at all. Further, it has been faid above (vit. 1.) that the acids precipitate a cryftalline fubftance from oxygenated muriat of iron. This fubftance I have found to contain manganefe. But what belongs to this place to obferve is, that it is not always, indeed it is but rarely, that this effect can be produced in any great degree: in a very fmall degree it may always be obferved; but, when I frit remarked it, the precipitate was very copious, fo that enough was readily collected for examination by the blow-pipe. The falt of manganefe does not thow this appearance in the imalleft degree. It depends, therefore, on fome peculiarity of the iron ruft, but precifely on what I cannot take upon we to determine.

As the oxygenated falis unite with all the other falts of the water, and confequently cannot be feparated by fpirit of wine, I have found it impolfible to determine the quantity of them.

I had concluded from the experiment ( $x$. ) that this water contained muriat of lime; and the following remark confrmed me in my error : I mention it, as I think it probable that others have been led into miltakes from the fame caufe. I reduced fome of the water, by evaporation, to about two ounce-meafures; taking for granted that by this procers A 22 nearly 
nearly the whole of the fulphat of lime was feparated. By adding fulphuric acid to this liquor, 20 grains of fulphat of lime were precipitated. I concluded, therefore, that this mult have proceeded from the decompofition of muriat of lime: in truth, this fulphat was diffolved in the two ouncemeafures of water, and was feparated by the decompofition of the oxygenated falt.

ON THE WATER OF THE OLD BATHS.

THE fpring which fupplies thefe baths was difcovered in I786, in which year a cold and a warm bath were conftructed. Upon finking the well, a rock was found at the depth of eighteen feet; and the water rifes from about the depth of three feet within the rock.

\section{THE GASEOUS FLUIDS.}

I could obtain very little gas from this water, not more than three cubic inches from a gallon. It was azotic. An hepatic fmell is perceptible when the water is frefh. To the hepatic gas, doubtlefs, it is owing, that no oxygen is found in this water or in that of the other fpring. Dr. Garnett has fo well explained the caufe of this circumftance, that it is needlefs for me to enter upon it. (See Dr. G. on the Mineral Waters of Horrowgate, p. 74, \&c.)

XVI. THE SPONTANEOUS PRECIPITATE.

This water is pellucid when it firf rifes from the fpring; in fmall quantities it does not lofe its tranfparency: a very fmall fediment is depofited by boiling, fo fmall indeed that fufficient cannot be collected in this way for examination. However, when the bath has been newly filled, in fome hours the tranfparency of this large body of water is deftroyed by expofure to the atmofphere, andit contracts a whitifh colour. I collected a large quantity of this precipitate from the bottom of the bath, where it by degrees accumulates. 1.I firlt attempted its analyfis by acids, but was difappointed. It is hardly foluble 
in any of the mineral acids : they all take up a little of it, make a brifk effervefcence, and excite heat when firft applied; but neither by a long digeftion, nor by boiling, could I faturate the acids; nor, by putting a very fmall quantity of the powder into a large quantity of acid, could I completely diffolve the powder.

2. But by the ufe of the blow-pipe it readily appeared that this fediment is no other than the oxydes of the two metais fo frequently mentioned, iron and manganefe. It may be made magnetic; it gives the hyacinthine calour to borax; the colour is deftroyed by continuing the fufion, and may be renewing by removing the globule to a filver fpoon: fufed with foda and nitre it makes a blue or a green globule. As the fediment may be procured in fufficient quantity, I repeated the laft experiment on a larger fcale: fome nitre being mixed with it, the mafs was pulverized, and fufed in a crucible; when taken out of the fire it was green, and diffolved in water, to which alfo it imparted a fine green calour: in a day or two a yellow ochre was depofited, when the folution became blue; from this liquor a powder fubfided by expofure to the air, which was manganefe. (See Scheele's Effay on Mang. xxxvi. B.)

3. Purfuing the obfervations of the effects of the mineral acids confirms this conclufion. I mixed fome of the fediment with powdered charcoal, and expofed the mixture to a ftrong red heat: it became of a light brown colour, and now proved to be readily foluble in all the mineral acids. (See Scheele's Eflay on Manganefe, xxxviii. A.) With the muriatic and nitric it formed a gelatinous compound. The fulphuric acid, diluted, was foon faturated; the liquor was evaporated, and depofited white cryftals, the form of which is rhomboidal. This is a triple falt, the bafe of which is iron and manganefe. If there be a fmall excefs of acid, the tafte is very like that of fulphat of argill. The fame falt may be obtained by boiling the fulphuric acid with the fediment itfelf, and continuing the boiling till the mafs is be- 
come dry : the falt may then be procured by lixiviating the dry mafs, and cryftallizing the folution.

\section{XVIT.}

Neither fulphat of argill nor oxygenated muriat of mercury is at all decompofed by this water.

XVIII. THE METALLIC SALTS.

All the appearances which demontrate the exiftence of peculiar metallic falts in the waters of the new baths are alfo to be found in this; as, the oxydation and folution of metals and a copious precipitate by galls, while the pruffiat of potafh is not affected (Iv.): and the fame experiments were repeated to how the prefence of the oxygenated falts of iron and manganefe (v. vir. \&cc.) with the fame refult, and atithorize the fame conclufions. Still I believe there is fome diff-ronce in regard to thefe falts between the two waters. I. I have already obferved ( XVIr.) two points of diftinction; and, as the fecond of thofe experiments is probably an indication of fulphur, this water feens to be without it. This is confirmed by evaporating the water in a filver veffel, to which it communicates no ftain. However, 2. Its action on copper is very ftrong, fo that, if it be boiled in a copper veffel for a long time, a blue oxyd of copper is feparated fron the veffel. But here, again, there is a difference between this and the former water ; for, though copper is diffolved in it, none can be precipitated on iron in its metallic form, as we have feen (1v. 1). The iron in this waterdoes not feem to be in that high degree of oxygrnation that it is in the other. This I infer, becanfe, 3 . the precipitate formed by tincture of galls is of a much darker colour, even when the water lias been nuch evaporated : fometimes, when the water has been reduced to half its original bulk, I have remarked eren a very night green tinge communicated by pruffiat of pot-ah, but not till it has been adcled to it many hours. 
As the oxygenated falts are formed by the action of hepatic gas on the metals, it cannot be doubted that they are very common. Bergman (Differt. vir. 6.) obferves, "that cold martial waters, when freth, almoft always have an hepatic fmell :" it feems very probable then that this falt of iron may be found in almoft all fuch waters. I doubt not that it has been frequently miftaken for muriat of lime, to which in its properties it approaches very nearly.

Though I have purpofely avoided all medical difcuffion in this effay, I cannot abftain from beftowing a moment's confideration on one very obvious queftion. What, it will be afked, are the medical properties of manganefe ? Is it ufeful ? Is it innocent? Is it noxious? That it is innoxious I certainly know. Dr. John Johnftone (Effay on Mineral Poifons, page 134.) has thown that it may be taken in large dofes without injury; and he has informed me, that he has fince confirmed the fame fact frequently. I wih I could as well anfwer the firft queftion; but what the medical virtues of this fubftance may be, is a fubject which ftill remains in a great meafure unexplored. It is certainly well worth the attention of men of fcience. To thofe who are inclined to labour in this feld I take leave to fugget, that they fhould we either the carbonator fome other falt of manganefe : the black oxyde, I apprebend, muft be hardly foluble in the banaan fluids.

\section{XEX. THE NEUTRAL SALTS.}

Thefe are the fame as of the other water, but in different quantities. The gallon contains of muriat of magnefia $5^{8} ;$ -muriat of foda 330 ; - fulphat of foda 62 grains.

\section{THE RESIDUUM.}

A fill larger refiduum is obtained, after the feparation of the neutral falts, from this than from the other water. The gallon leaves 146 grains. Its properties are the fame as of that already defcribed ( $\mathrm{X}$ V). 
It is to be obferved, that both thefe fprings are affected by rainy weather; and that, confequently, their contents vary confiderably according to the feafons.

WY NOPTICAL TABLE OF SUBSTANCES CONTAINED IN THE TWO SPRINGS.

Gafeous fluids contained in a wine-gallon in cubic inches.

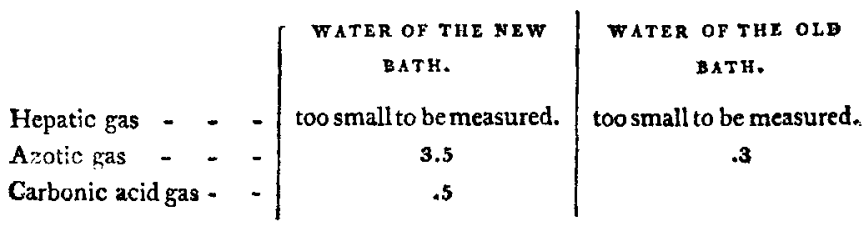

Solid contents of a wine-gallon in grains.

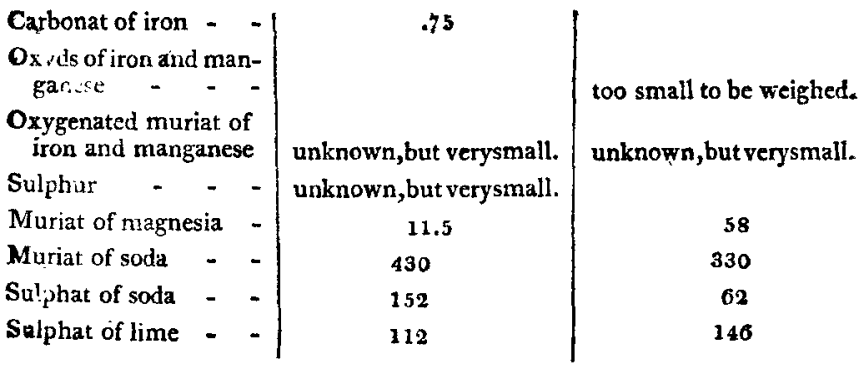

ExtraEZ of a letter from Dr. Ho c м E, dated Sept. $25 t h$, 1797 .

"In the analyfis of the waters of the new baths I have conjectured that the decompofition of oxygenated muriat of mercury is occafioned by a minute portion of fulphur, attached to fome of the fubftances diffolved in the water (111.). I have attempted to verify this conjecture, and not without fuccefs. Wifhing to collect fome quantity of the precipitate, I evaporated a gallon of the water to half its bulk; but found, that now the falt of mercury was diffolved witheut decompofition. I added, therefore, the falt to the water without boiling; and fuffered the precipitate to fubfide. By this procefs, I could collect no more than a grain from a gallon of water. I threw this upon alkali heated to rednefs; but 
the whole inftantly evaporated with a denfe finoke. I nixed, therefore, another portion (procured in the fame manner) with alkali, and heated them in a crucible : ftill I failed to collect any fulphur from the alkali (as I had hoped); but I now perceived that, as the crucible became hot, the matter burnt away with a blue flame, as fulphur does.

"Sulphat of argill is not decompofed by this water when it has been reduced by evaporation : however, it gradually feparates fome of the abundant fulphat of lime; which is probably caufed by its attracting the water which held it in folution.

"I think it right here to obferve, that $I$ have recently met with this water in fuch a condition that it caufed a permanent decompofition of fulphat of argill. This precipitate is extremely minute: I have not as yet determined the caufe of it, but I fufpect it to be carbonat of magnefia."s

V. Second Memoir on the Metal contained in the Red Lead of Siberia. By Cit. Vauquelin. From the Annales de Chimie, Vol. XXV. 7798.

I

HAVE already thown in my firf memoir on the red lead of Siberia, that this mineral contains a particular metal, which I promifed to examine with more attention. The Council of Mines having furnithed me with a pretty large quantity of the red lead, confidering its fcarcity, I have been able to make a feries of experiments fufficient to determine its principal properties, of which I thall now give an account ; but it will firf be neceffary to recapitulate, in a few words, the fubltance of my former memoir, in order that what I have to fay at prefent may be rendered more intelligible.

I. I thall obferve, that on boiling the red lead reduced to 2 powder with two parts of the carbonat of pot-a?h, the lead

* See page 279. 